\title{
Municipalities' Decision to Care: At Home or in a Nursing Home
}

\author{
Theis $^{\text {Theisen }}{ }^{1}(\mathbb{D}$
}

Accepted: 23 September 2020 / Published online: 29 October 2020

(C) The Author(s) 2020

\begin{abstract}
An almost ideal demand system for long-term care is estimated using data from Norway, where the split of long-term care between home care and care in nursing homes is determined by municipalities. Previous literature has barely addressed what determines municipalities' or other organizations' allocations of resources to the subsectors of long-term care. The results show that home care is a luxury, while nursing home care is a necessity with respect to total expenditures on long-term care. Municipalities respond to high unit costs for home care by reducing that type of care. Municipalities are highly responsive to variations in the need for the two types of care and seem to provide a well-functioning insurance mechanism for long-term care. In the previous empirical literature, municipalities' role as providers of insurance against the consequences of disabilities and frailty has received scant attention.
\end{abstract}

Keywords Local government spending $\cdot$ Long-term-care $\cdot$ Home care $\cdot$ Nursing home care

JEL Classification $\mathrm{H} 72 \cdot \mathrm{H} 75 \cdot \mathrm{J} 14 \cdot \mathrm{I} 13 \cdot \mathrm{I} 18$

\section{Introduction}

The population of industrialized countries is ageing. In the years to come, new countries will join the club of ageing societies. Numerous studies have documented that the use of long-term care (LTC) increases as people age or if people have a disability, which is a correlate of age. Hence, the LTC sector has grown over time, in

Electronic supplementary material The online version of this article (https://doi.org/10.1007/s11294-02009806-z) contains supplementary material, which is available to authorized users.

Theis Theisen

Theis.Theisen@uia.no

1 Department of Economics and Finance, School of Business and Law, University of Agder, P.O. Box 422, 4604 Kristiansand S, Norway 
tandem with the ageing population. The challenges raised by increasing demand for LTC have been met in different ways around the world. In countries like the U.S. and Germany, insurance-based systems play an important role, with for-profit or non-profit organizations being major actors both in paying the bills for LTC and in providing care for those insured. Under such systems, eligibility rules regulate entrance to LTC (Rahman et al., 2016). In contrast, if the public sector is the main provider of LTC services, like in the UK and the Scandinavian countries, budget constraints and need assessments play an important role. In this paper, the focus is on public provision, represented by the case of Norway, where formal LTC is almost exclusively provided through the public sector. However, many of the issues addressed will also be relevant to other countries.

In the public sector, resources are commonly allocated through stepwise processes, with political decision-making at the higher levels and bureaucratic or professional decision-making at the lower levels. In the Scandinavian context, resources are first allocated from the central government to municipalities. Next, the local government assembly allocates the municipality's budget to the main sectors, such as LTC and education. At the third step, sector budgets are allocated to sub-sectors of LTC. In this paper, the focus is on the third level of decision-making, i.e. what determines the capacity of the nursing home sector and the home care sector in municipalities. Since caring for an individual in a nursing home usually is far more expensive than home care, this issue is of great importance to the public sector, which in many countries covers most of the costs for nursing home care, as well as home care. It is also important to care recipients themselves, who may have to pay high fees for nursing home care, and whose quality of life may be profoundly affected by the form of care they receive. Finally, the balance between care at home and in nursing homes may be important to informal caregivers who carry part of the caring burden in the case of home care, and to relatives who may receive smaller bequests if family members become institutionalized.

Many researchers have addressed an individual's choice between institutional care and home care if free to choose (Mommaerts 2018). This is certainly an important question, but for countries where decisions on LTC are taken in the stepwise manner just described, the choice between the two forms of care should be examined at every step of the decision process. In the sequel, such an investigation is carried out by estimating a model that identifies what determines municipalities' allocation of LTC resources between home care and nursing home care. This issue has received scant attention in the economics literature.

The model estimated herein sheds light on several important research questions in public sector decision-making: (1) How will a municipality split an increase in funds available for LTC between home care and nursing home care? The results show that home care will increase more than nursing home care. (2) Will an increase in central government unconditional block grants, with a clearly stated intention to increase municipalities' supply of nursing home beds, meet the goal? The results provide convincing evidence that it will not. (3) To what extent do municipalities substitute home care for nursing home care? The results indicate only a slight substitution. (4) How do municipalities accommodate differences in morbidity and mortality in their supply of the two forms of care? The results indicate that they do so very well. (5) Does the provision of LTC by municipalities function well as an insurance mechanism 
against an individuals' loss of functionality? According to the results, they do function quite well in this respect.

\section{Institutional Setting}

Since 1988, Norwegian municipalities have had full responsibility for, and full discretion in, providing nursing home care and home care. LTC in the form of home care and nursing home care account for one-third of Norwegian municipalities' expenditures. ${ }^{1}$ Under nursing homes, a few old peoples' homes are also subsumed. Home care includes home nursing and home help. Since commercial providers offering LTC services in a competitive market have not played a significant role in Norway, they are not included in the analysis. ${ }^{2}$

Norwegian municipalities finance LTC and other services mainly through block grants from the central government and taxes on income and wealth. Through the system of central government block grants, municipalities are, in principle, fully compensated for the additional costs of having a population in need of care services, for example, having many children requiring daycare and schools and having a costly geographical structure. Block grants are functions of variables that are hardly influenced by municipalities themselves, e.g. age structure and geographical characteristics. Most importantly, block grants do not depend on either the volume of LTC services or the internal structure of the LTC sector. Differences in per capita revenues from taxes on income and wealth are largely compensated through the grant system, but income differences between municipalities remain in the upper part of the income distribution. Since central government block grants are exogenous and all municipalities tax incomes and wealth at the maximum legal rates, these revenues, amounting to $90 \%$ of municipalities' revenues, are exogenous. The remaining $10 \%$ of revenues derive mainly from user fees and the property tax. ${ }^{3}$

In accordance with central government bylaws, home nursing is provided free of charge, while municipalities may charge an income-dependent user fee for home help. The fee is determined by the local government assembly, but within the framework laid down in the central government bylaws (Lovdata 2012), thus considerably limiting the variation in user fees. On average, home-help user fees cover merely $1 \%$ of municipalities' current costs of home care. As per central government bylaws, nursing-home

\footnotetext{
${ }^{1}$ Education and child care account for another one-third. The remaining one-third includes administration, fire department, cultural services, utilities and infrastructure.

${ }^{2}$ Private firms exist that have signed contracts to produce care services for municipalities. However, irrespective of ownership, municipalities carry the financial responsibility for LTC. Even if the service producer is a private organization or firm, municipalities decide which individuals to admit to nursing homes, and the volume of home care individuals is allotted. User fees are also the same when the service producer is a private organization as when it is the municipality itself. These fees are laid down in central government bylaws and in decisions of the municipalities. A small sector of private homemaking firms exists, but customers of these firms are, in general, relatively young, are active in the labor market, have high incomes, and pay the full costs for the services. Such individuals do not receive LTC services, hence private homemaking firms are not included in the analysis. Additional information on the role of non-government actors in Norwegian LTC can be found in Sivesind (2017).

${ }^{3}$ In 2016, municipalities could tax properties at a maximum $0.7 \%$ of the assessed value. Of the $85 \%$ of municipalities that had property taxes in 2016 , most applied the maximum rate.
} 
user fees are income dependent (Lovdata 2012). Since the national government determines the scale of income dependence, user fees for each nursing home resident will be exogenous to municipalities, depending mainly on the resident's income from pensions and capital. In the Norwegian pension system, an individual's pension is a function of labor income up to the age of retirement. Even if almost all nursing-home residents are charged a fee of $75-85 \%$ of their after-tax income, for most the fee is far below unit costs. The fee cannot exceed municipalities' current costs, but extremely few individuals reach this fee ceiling. On average, user fees for nursing homes amount to only $13 \%$ of municipalities' current gross costs per nursing home resident. Inter alia due to the heavily subsidized user fees, the aggregate supply of LTC in Norwegian municipalities falls short of individuals' demand. Hence, LTC services are rationed to care recipients.

On average, wage expenditures amount to almost $83 \%$ of Norwegian municipalities' current gross expenditures on LTC. Wage rates at the local level are taken to be exogenous, and the same is the case for, for example, unit prices of medicines, food and energy. 4

\section{Empirical Model of the LTC Sector}

Following Barr and Davis (1966), assume that municipalities are guided by a grand utility function representing the preferences of the ruling political party or coalition. Also, assume a weakly separable grand utility function, containing a sub-utility function for LTC. A municipality's utility of LTC is a function of home care and nursing home care provided. Under these assumptions, one may apply the theory of two-stage budgeting (Deaton and Muellbauer, 1980a, 120-136). At the first stage, resources are allocated between the main sectors, such as LTC and education. At the second stage, LTC resources are allocated to care at home and to nursing homes, each of which will be a function of the total LTC budget and the unit costs for home care and nursing home care. This modelling approach incorporates the assumption that municipalities typically target services towards distinct groups, like the elderly and children, and that the utility a municipality derives from LTC is unlikely to depend directly on the volume of other services. An advantage of restricting attention to the sector-specific allocation problem is that it may be easier to obtain well-defined unit costs for the two main services in the LTC sector than for many other services provided by municipalities. Another advantage is that one may benefit from using an established model like the almost ideal demand system (AIDS) of Deaton and Muellbauer (1980b) as a vehicle for modelling municipalities' allocation of care. The AIDS model implies the budget share equation:

$$
w_{i}^{m}=A_{i}^{m}+\sum_{j=H, N} \gamma_{i j} \log p_{j}^{m}+\beta_{i} \log \left(r^{m} / P^{m}\right),(i=H, N),
$$

\footnotetext{
${ }^{4}$ Each year wages are negotiated between labor unions and the organizations of local government employers. First, through negotiations at the national level, one can determine: (1) a wage schedule defining wage rates of local government employees as a function of their position and seniority, and (2) a common framework for negotiations in each municipality. In local negotiations, wages of individual employees may be adjusted according to the national wage-schedule but within the framework for local negotiations. Falch and Strøm (2006) found that local negotiations have increased the wage dispersion among Norwegian municipalities slightly, but the numerical magnitudes are very small.
} 
where $m$ indexes municipalities, $i$ indexes home care $(H)$ or nursing home care $(N), w_{i}^{m}$ is the expenditure share of type- $i$-care, $p_{j}^{m}(j=H, N)$ is the net unit cost of the two types of care, $r^{m}$ is the municipality's net per capita expenditures on LTC, $P^{m}$ is a cost index for LTC, and $A_{i}^{m}, \gamma_{i j}$ and $\beta_{i}$ are parameters to be estimated. Törnqvist's cost index, ${ }^{5}$

$$
\log P^{m}=\frac{1}{2} \sum_{j=H, N}\left[w_{j}^{m}+w_{j}^{\bar{m}}\right] \log \left(p_{j}^{m} / p_{j}^{\bar{m}}\right),
$$

is used, with $\bar{m}$ denoting the reference municipality. Törnqvist's index fulfills the properties usually required in index theory. It is an intermediate index between Laspeyre's and Paasche's index, and it approximates closely Fisher's ideal index. Next, like inter alia Heien and Pompelli (1989), the baseline version of the AIDS model is extended by assuming:

$$
A_{i}^{m}=\alpha_{i 0}+\sum_{d=1}^{D} \alpha_{i d} z_{d}^{m}(i=H, N)
$$

where $z_{1}^{m}, \ldots, z_{D}^{m}$ are exogenous municipality characteristics, while $\alpha_{i 0}$ and $\alpha_{i d}$ 's are parameters to be estimated. Substituting from Equation (3) into Equation (1) yields expenditure share equations:

$$
\begin{aligned}
w_{i}^{m}= & \left(\alpha_{i 0}-\beta_{i} \log \varphi_{l}\right)+\sum_{d=1}^{D} \alpha_{i d} z_{d}^{m}+\sum_{j=H, N} \gamma_{i j} \log \left(p_{j}^{m}\right)+\beta_{i} \log \left(r^{m} / P^{m}\right) \\
& +\varepsilon_{i}^{m}(i=H, N)
\end{aligned}
$$

where $\varphi_{l}$ is an index-specific constant, while $\varepsilon_{i}^{m}$ is a stochastic error term for which it is assumed that $E\left(\varepsilon_{i}^{m} \varepsilon_{j}^{m}\right)=\sigma_{i j}^{m}, \forall m$, and $E\left(\varepsilon_{i}^{m} \varepsilon_{j}^{m^{\prime}}\right)=0, m \neq m^{\prime}, i, j=H, N$.

If the restrictions of adding up homogeneity and symmetry are fulfilled (Online Supplemental Appendix), the AIDS model is consistent with each municipality maximizing utility subject to a budget constraint. In the absence of differences in unit costs and real per capita net income across municipalities, budget shares in the AIDS model are given by $A_{i}^{m}$, which in generally differs between municipalities. Additional differences in budget shares arise if unit costs and real LTC expenditures differ between municipalities. The AIDS model will be estimated using cross-sectional data. This implies that the estimated relationships are supposed to capture the factors that in the long run affect the allocation of LTC resources.

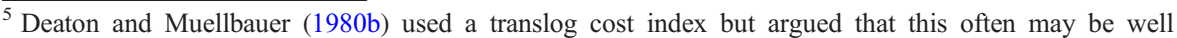
approximated by the index suggested by Stone (1953). However, Pashardes (1993) demonstrated that the Stone index in the AIDS model introduces an omitted-variable problem. Moschini (1995) argued against the Stone index since it does not possess the properties usually required in index number theory. Instead, Moschini suggested using a standard index like Laspeyre's, Paasche's or Törnqvist's.
} 


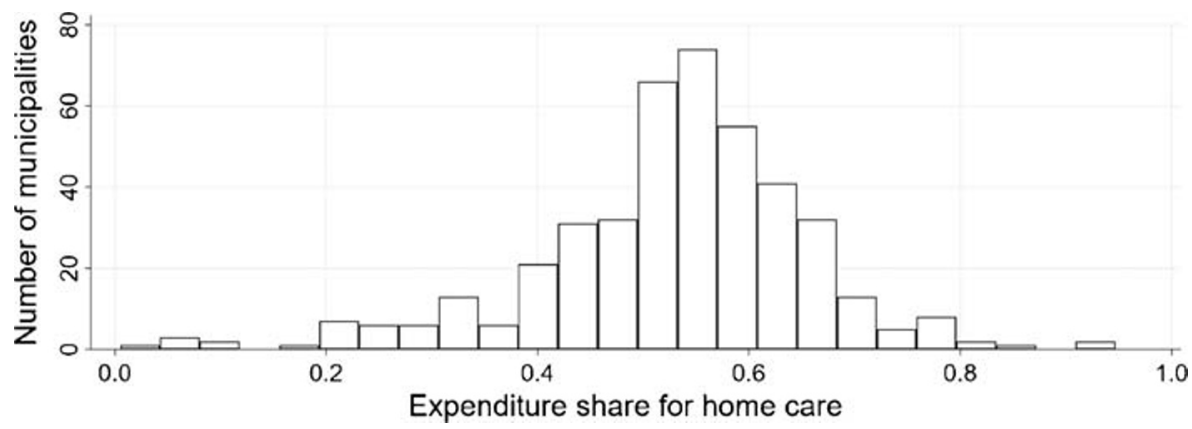

Fig. 1 Expenditure share for home care in Norwegian municipalities for 2016. Source: Author's calculation based on data from Statistics Norway (2020a, b, c, d, e, f, g, h, i, j)

\section{Data and Descriptive Analysis}

Data for the 428 Norwegian municipalities existing in 2016 were used in the empirical analysis. On average, municipalities allocated 53\% of LTC expenditures to home care and $47 \%$ to institutional care, but from Fig. 1 it is evident that the shares differ substantially between municipalities. For decades, researchers have been puzzled by the large variation in the forms of care Norwegian municipalities offer.

Variable definitions are provided in Table 1. Descriptive statistics are in the Online Supplemental Appendix Table 1. The standard deviations of the unitcost variables in Online Supplemental Appendix Table 1 are modest compared to their mean value, but the tails of the distributions are somewhat longer than expected. In accordance with Borge et al. (2013), one may argue that this mainly is due to $\mathrm{x}$-inefficiency in municipalities' service production, but the possibility that errors of observation also may play a role cannot be excluded. ${ }^{6}$

In computing Törnqvist's unit-cost index, the municipality with the median $w_{H}^{m}$ is the reference. In 2016, this municipality had an expenditure share for home care of $w_{H}^{\bar{m}} \approx 0.54$, an annual unit cost, $p_{N}^{\bar{m}}$, per nursing home bed of 115,463 USD (1,045,897 NOK), and an annual cost, $p_{H}^{\bar{m}}$, of providing 1 hour of

\footnotetext{
${ }^{6}$ The quality of the two unit-cost variables crucially depends on the quality of municipality accounting data on gross expenditures in the two sectors, the quality of the user-fee data and the quality of the volume data on hours of home care and number of nursing home beds. No strong reasons were present to suspect serious deficiencies in the accounting data for gross expenditures or user fees, since these data are registered in a common accounting system for all Norwegian local governments, established many years ago. It would be somewhat less surprising if errors occured in the data on the number of nursing-home beds or hours of home care provided. These data derive from IPLOS (Register for statistics on municipal health and care services), which was established in 2006. It is known that errors have occurred in the IPLOS-data. Such errors may result in erroneously high or low unit costs in some municipalities. Economies of scale may be an alternative explanation for variations in unit costs. McKay (1988) and Filippini (2001) found economies of scale in nursing homes, while Dudzinski et al. (1998) found diseconomies of scale in home care. To examine whether economies or diseconomies of scale may be a reason for extreme magnitudes of unit costs in the nursing home data, the logarithm of municipality unit costs for nursing homes was regressed on the logarithm of nursing home beds and the variable Urban defined in Table 1. Similarly, the logarithm of unit costs for home care was regressed on the logarithm of hours of home care provided and Urban. Like in Borge et al. (2013), none of these relationships showed evidence of deviations from constant returns to scale.
} 
Table 1 Variable definitions

Homeshare Gross current expenditures on home care minus user fees for home care, divided by total LTC expenditures.

Nursingshare Gross current expenditures on nursing home care minus user fees for nursing home care, divided by total LTC expenditures.

Home-cost Gross current expenditures on home care minus user fees for home care, divided by the number of hours of home care provided.

Nurse-cost Gross current expenditures on nursing homes minus user fees for nursing homes, divided by the number of nursing home places.

Cost index Törnqvist's cost index, $P^{m}$, defined by Equation (2).

Expend Gross expenditures on home care and nursing home care, minus incomes from user fees on home care and nursing home care, calculated per capita and divided by $P_{T O}^{m}$.

Income Municipality's per capita incomes from block grants and taxes.

Young Number of individuals aged 0-15 divided by the total population.

Age 67-79 Number of individuals aged 67-79 divided by the total population.

Age 80-89 Number of individuals aged 80-89 divided by the total population.

Age $90+\quad$ Number of individuals 90 and above divided by the total population.

Expdeaths $\quad$ Expdeaths $=\left(\frac{\sum_{j=1}^{105} \omega_{j}^{\text {FEMALE }} N_{j m}^{\text {FEMALE }}+\sum_{j=1}^{105} \omega_{j}^{\text {MALE }} N_{j m}^{\text {MALE }}}{\sum_{j=1}^{105} N_{j m}^{F E M A L E}+\sum_{j=1}^{105} N_{j m}^{\text {MALE }}}\right)$. Here $\omega_{j}^{\text {FEMALE }}$ and $\omega_{j}^{\text {MALE }}$ are one-year-class death rates in 2016 for females and males in the Norwegian population, $N_{j m}^{F E M A L E}$ and $N_{j m}^{M A L E}$ are the number of females and males in age class $j$ in municipality $m$. Age-classes 105 and above are collapsed into one class.

Mortality $\quad$ Mortality $=$ Expdeaths $-\left(\left(D_{2015}^{m}+D_{2016}^{m}+D_{2017}^{m}\right) / 3\right) / N^{m}$, where $D_{t}^{m}$ is the number of persons in municipality $m$ that died in year $t(t=2015,2016,2017)$, and $N^{m}$ is the population in 2016.

Unmarried Share of the population in 2016 that is unmarried.

Female Share of females aged 40-74 that participate in the labor market.

Urban Share of the population that lives in urban settlements.

$\mathrm{Pv} \quad$ Dummy variables equal to 1 if the municipality's population in the interval $(v-1000, v)$, otherwise $0 ; v$ taking values 1000, 2000, 3000, 4000, 5000.

P-spline $\quad \psi\left(N^{m}\right)=\operatorname{Ln}\left(N^{m} / 4500\right)$ if population $\leq 4500,0$ it not. $N^{m}=$ population.

Sheltered Number of sheltered dwellings divided by the population.

Medianvoter Median age of individuals 18 years of age and above.

Socialists Share of socialists in the local government assembly.

Herfindahl $H E R F=\sum_{g=1}^{G} s_{g}^{2}$, where $s_{g}$ is party $g$ 's share of representatives in the local government assembly, $G$ the number of parties. $\operatorname{HERF} \in(0,1]$.

home care per week during all 52 weeks of a year amounting to 1604 USD $(14,524 \mathrm{NOK}){ }^{7}$ Hence, in the reference municipality, the net costs of providing nursing home care for an individual for one full year correspond to the net costs of providing an individual 3744 hours of home care per year, i.e. 10.3 hours per day. Very few home care users receive so many hours.

\footnotetext{
7 Throughout the paper, numbers in Norwegian crowns (NOK) are converted to USD by using the exchange rate published by the Norwegian Central Bank on July 31, 2020, i.e. 9.0583 NOK/USD (Norges Bank 2020).
} 


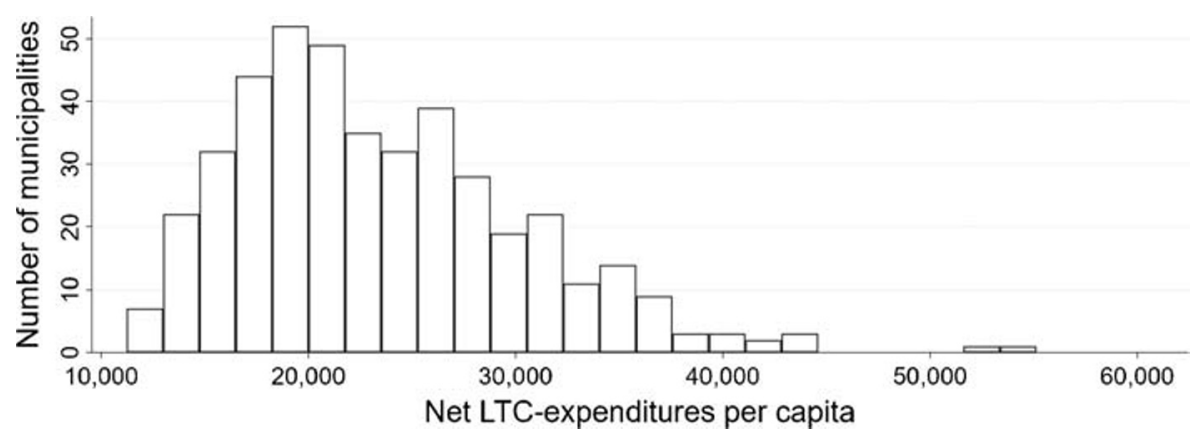

Fig. 2 Net LTC expenditures per capita in Norwegian municipalities for 2016. Source: Author's calculations based on data from Statistics Norway (2020a, b, c, d, e, f, g, h, i, j)

Therefore, to a municipality, the costs of providing home care are, for most individuals served, far below the costs of caring for these in a nursing home.

Figure 2 reveals that the lower tail of the expenditure distribution for LTC is quite compressed. This is most likely due to the central government grant system, with an absolute lower threshold below which Norwegian municipalities' incomes from income and wealth taxes and central government grants cannot fall.

\section{Empirical Results and Robustness Checks}

Table 2 contains estimation results for three versions of the linear AIDS model. Specification B differs from Specification A only in that the ageclass variables are replaced by the more parsimonious measure Expdeaths, and Specification C differs from Specification B only in that population dummies are replaced by a non-linear spline-function. Since Specification B outperforms the other specifications, both when judged by the adjusted Rsq. and the Akaike information criterion, the focus in the sequel is solely on Specification B. The Vif-statistics for Specification B indicate that regressors are not co-linear, and the Ramsey test statistic strongly indicates that the linear version of the AIDS model is fully satisfactory. Moreover, the Breusch-Pagan statistic reveals that the use of variables that are either logtransformed or measured as shares successfully removes heteroskedasticity. Nevertheless, robust standard errors estimated with the Huber-White sandwich estimator are used throughout. ${ }^{8}$ Specification B was also estimated with other price indexes, by seemingly unrelated regressions (Zellner 1962) and by maximum likelihood, but since these results only differ marginally from those in Table 2, they are relegated to Online Supplemental Appendix Tables 2 and 3. Finally, a Wald-test of the homogeneity restriction rejected the null hypothesis that this restriction is valid $(p<0.01)$.

\footnotetext{
${ }^{8}$ For Specification B, clustered standard errors have also been considered. Since these differed little from the robust standard errors in Table 2, these results are not reported.
} 
Table 2 Estimation results for home care equation

\begin{tabular}{|c|c|c|c|c|}
\hline \multirow[t]{2}{*}{ Variable } & \multicolumn{3}{|c|}{ Estimation based on full sample } & \multirow{2}{*}{ Tails excluded } \\
\hline & Specification A & Specification B & Specification $\mathrm{C}$ & \\
\hline \multirow[t]{2}{*}{ Ln(Home-cost) } & $.0875 * * *$ & $.0908 * * *$ & $.1125 * * *$ & $.0740 * *$ \\
\hline & $(.0190)$ & $(.0190)$ & $(.0198)$ & $(.0263)$ \\
\hline \multirow[t]{2}{*}{ Ln(Nurse-cost) } & .0037 & .0042 & .0083 & -.0279 \\
\hline & $(.0258)$ & $(.0256)$ & $(.0250)$ & $(.0371)$ \\
\hline \multirow[t]{2}{*}{ Ln(Expend) } & $.1025 * * *$ & $.1061 * * *$ & $.1402 * * *$ & $.1055^{* *}$ \\
\hline & $(.0282)$ & $(.0286)$ & $(.0299)$ & $(.0368)$ \\
\hline \multirow[t]{2}{*}{ Age $67-79$} & -.3791 & & & \\
\hline & $(.5150)$ & & & \\
\hline \multirow[t]{2}{*}{ Age $80-89$} & -1.1300 & & & \\
\hline & $(.7804)$ & & & \\
\hline \multirow[t]{2}{*}{ Age 90-D } & $-5.609 * *$ & & & \\
\hline & $(1.923)$ & & & \\
\hline \multirow[t]{2}{*}{ Expdeaths } & & $-20.8400 * * *$ & $-22.4800 * * *$ & $-20.9800 * *$ \\
\hline & & $(5.563)$ & $(5.616)$ & $(7.0930)$ \\
\hline \multirow[t]{2}{*}{ Mortality } & -7.4500 & -7.808 & -6.235 & $-9.8260 *$ \\
\hline & $(4.012)$ & $(4.038)$ & $(4.031)$ & $(4.7030)$ \\
\hline \multirow[t]{2}{*}{ Unmarried } & .1251 & .1371 & .0567 & .0260 \\
\hline & $(.1627)$ & $(.1625)$ & $(.1604)$ & $(.1931)$ \\
\hline \multirow[t]{2}{*}{ Female } & -.0735 & -.0847 & -.0823 & -.1330 \\
\hline & $(.1153)$ & $(.1111)$ & $(.1160)$ & $(.1243)$ \\
\hline \multirow[t]{2}{*}{ Urban } & .0148 & .0143 & .0069 & .0132 \\
\hline & $(.0268)$ & $(.0268)$ & $(.0244)$ & $(.0314)$ \\
\hline \multirow[t]{2}{*}{ P1000 } & $-.3002 * * *$ & $-.2989 * * *$ & & $-.3029 * * *$ \\
\hline & $(.0254)$ & $(.0252)$ & & $(.0313)$ \\
\hline \multirow[t]{2}{*}{ P2000 } & $-.1234 * * *$ & $-.1217 * * *$ & & $-.1282 * * *$ \\
\hline & $(.0189)$ & $(.0184)$ & & $(.0224)$ \\
\hline \multirow[t]{2}{*}{ P3000 } & $-.0738 * * *$ & $-.0739 * * *$ & & $-.0865^{* * *}$ \\
\hline & $(.0174)$ & $(.0172)$ & & $(.0190)$ \\
\hline \multirow[t]{2}{*}{ P4000 } & $-.0562 * *$ & $-.0554 * *$ & & $-.0762 * * *$ \\
\hline & $(.0207)$ & $(.0206)$ & & $(.0192)$ \\
\hline \multirow[t]{2}{*}{ P5000 } & -.0108 & -.0096 & & -.0121 \\
\hline & $(.0176)$ & $(.0177)$ & & $(.0220)$ \\
\hline \multirow[t]{2}{*}{ P-spline } & & & $.1472 * * *$ & \\
\hline & & & $(.0126)$ & \\
\hline \multirow[t]{2}{*}{ Sheltered } & $5.0500 * * *$ & $5.0510 * * *$ & $4.395 * * *$ & $5.294 * * *$ \\
\hline & $(.9372)$ & $(.9215)$ & $(.8980)$ & (1.083) \\
\hline \multirow[t]{2}{*}{ Medianvoter } & .0046 & .0068 & .0068 & .0066 \\
\hline & $(.0039)$ & $(.0036)$ & $(.0036)$ & $(.0045)$ \\
\hline \multirow[t]{2}{*}{ Socialists } & -.0187 & -.0182 & -.0185 & .0061 \\
\hline & $(.0406)$ & $(.0404)$ & $(.0403)$ & $(.0451)$ \\
\hline
\end{tabular}


Table 2 (continued)

\begin{tabular}{lllll}
\hline Variable & \multicolumn{2}{l}{ Estimation based on full sample } & Tails excluded \\
\cline { 2 - 4 } \cline { 4 - 4 } & Specification A & Specification B & Specification C & Specification B \\
\hline Herfindahl & $-.3091^{* * *}$ & $-.306^{* * *}$ & $-.2672^{* * *}$ & $-.2833^{* * * *}$ \\
& $(.0591)$ & $(.0578)$ & $(.0554)$ & $(.0652)$ \\
Constant & $-1.418^{*}$ & $-1.563^{*}$ & $-2.095^{* *}$ & -.8553 \\
& $(.6606)$ & $(.6672)$ & $(.6731)$ & $(.8534)$ \\
R-sq. & .5353 & .5371 & .5255 & .5497 \\
R-sq. adj. & .5136 & .5179 & .5106 & \\
F & 24.73 & 27.98 & 35.27 & 22.69 \\
AIC & -819.205 & -824.902 & -822.284 & -659.365 \\
BIC & -738.022 & -751.838 & -765.457 & -590.764 \\
Vif average & 2.94 & 2.38 & 2.62 & 2.33 \\
Vif max & 6.95 & 6.13 & 6.07 & 6.13 \\
Ramsey & 0.39 & 0.20 & 2.13 & 0.86 \\
Breusch-Pagan & 2.42 & 2.67 & 3.09 & 3.51 \\
N & 428 & 428 & 428 & 334 \\
\hline
\end{tabular}

Home care equation in linear two-sector AIDS model using Törnqvist's unit-cost index and data from 2016. Estimated by ordinary least squares. Dependent variable: Homeshare. Robust standard errors in parentheses. Statistical significance indicated by: $* * * p<0.001, * * p<0.01, * p<0.05$. Source: Statistics Norway $(2020 \mathrm{a}, \mathrm{b}$, $\mathrm{c}, \mathrm{d}, \mathrm{e}, \mathrm{f}, \mathrm{g}, \mathrm{h}, \mathrm{i}, \mathrm{j}$ ) and further processed by the author

Possible endogeneity problems related to expenditures were addressed by an instrumental variable approach, but the case for instrumenting the deflated expenditure variable does not seem to be particularly strong. ${ }^{9}$ The fact that a measure of the quality of care has not been available might be viewed as an omitted variable problem. According to Filippini (2001), Swiss nursing homes providing high-quality services had higher unit costs. Vitiliano and Toren (1994) found similar results for nursing homes in New York. Swiss and U.S. nursing homes are much more heterogeneous than Norwegian nursing homes. In Norway, nursing home care is quite standardized, due to central government regulations of physical facilities, services provided, required competence of employees and staffing norms, for example. Hence, the lack of quality indicators is likely to be much less problematic than if data from a country with more heterogeneous nursing homes had been used. Notice also that Kjøs

\footnotetext{
${ }^{9}$ Deflated LTC was instrumented by: (1) municipalities' exogenous incomes from central government block grants and taxes on income and wealth (Income), and (2) the share of individuals in the municipality below 15 years of age (Young). The first-stage regressions in the just identified instrumental variables model with $\operatorname{Ln}$ (Expend) instrumented by $\ln ($ Income $)$ as well as in the over-identified model including also Young as an instrument, had a good fit (R-sq. higher than 0.75 ). However, a Hansen-Sargan test rejected the validity of the two instruments in the over-identified model, and a Durbin-Wu-Hausmann test did not reject the assumption that the deflated expenditure variable is exogenous. However, the results for the second-stage regressions in both the just identified and in the overidentified model turned out to have a low fit, with very few statistically significant coefficients.
} 
and Havig (2016) did not find any relationship between staffing and quality of care in Norwegian nursing home wards (with 8-12 residents). Similar arguments may be made for home care.

As noted in the previous section (footnote 6), errors-of-measurement in the unit-cost variables might occur, perhaps in particular for observations in the high or low end of the distribution of the two unit-cost variables. In principle, this problem, as well as possible problems related to omitted variables correlated with the unit-cost variables, could be handled through instrumenting unit-cost variables, but after having considered several instruments it was concluded that they all turned out to be much too weak to be useful. To examine the implications of possible measurement errors in the unit-cost variables more closely, the 25 observations with the highest and lowest unit costs for as well home care as nursing home care were detected and Specification B was reestimated from the sub-sample excluding the four tails, i.e. a sample of 334 municipalities. The estimation results are shown in Table 2 as Specification B: Tails excluded. Notice that the expenditure coefficient in Specification B is almost identical when estimation is based on the tails-excluded sample as when the full sample is used. The estimated coefficient of the home care unit-cost variable in Specification B with tails excluded is about $19 \%$ smaller than when based on the full sample, but the difference between the two coefficients is not statistically significant.

\section{Discussion of Policy Issues}

The positive sign carried by the coefficient affiliated with LTC expenditure implies that home care is a luxury with respect to net LTC expenditures, and nursing home care a necessity. For the reference municipality, the elasticities are $E_{H} \approx 1.20$ and $E_{N} \approx 0.77$. $^{10}$ Hence, if resources available to the LTC sector increase, municipalities expand the capacity of the home care sector more than the bed capacity of nursing homes. However, almost all municipalities have expenditure elasticities in the ranges $E_{H} \in$ $(1.1,1.6)$ and $E_{N} \in(0.5,0.9)$.

It is also of interest to examine if home care is a luxury when considering the allocation between major sectors in the municipality. Attention is limited, however, to the allocation between two sectors: LTC and all remaining sectors. The specification is inspired by Poterba (1997), and estimation results shown in Table 3 imply an upperstage expenditure elasticity for LTC of 0.73 , which strongly indicates that the aggregate good LTC is a necessity in Norwegian municipalities. Moreover, combining the results for the lower-stage and upper-stage allocation, the overall expenditure elasticity (with respect to municipalities' incomes) for home care in the reference municipality can be calculated as 0.88 , and for nursing home care as 0.56 . Hence, both types of care seem to be necessities in most municipalities' overall decisions. This result is in accordance with an initiative of the Norwegian central government at the end of 2010 to increase the number of nursing home beds by 10,000 through an increase in general grants,

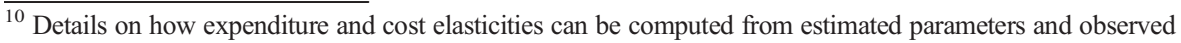
variables are provided in the Online Supplemental Appendix. Moreover, Table 4 in the Online Supplemental Appendix contains summary statistics for expenditure elasticities as well as for all uncompensated and compensated elasticities. This table also shows that the calculated mean elasticities differ little from the elasticities of the reference municipality.
} 
Table 3 Estimation results for upper stage allocation $(N=428)$

\begin{tabular}{llr}
\hline Ln(Income) & $.7313^{* * *}$ & $(.0580)$ \\
Cost index & $.0955^{*}$ & $(.0401)$ \\
Expdeaths & $45.07 * * *$ & $(5.789)$ \\
Young & $-1.997 * * *$ & $(.5280)$ \\
Unmarried & $.5792^{*}$ & $(.2625)$ \\
Constant & 1.553 & $(.6918)$ \\
R-sq. & .6996 & \\
\hline
\end{tabular}

Dependent variable: Logarithm of per capita expenditures on LTC. Estimated by ordinary least squares. Robust standard errors in parentheses. Statistical significance indicated by: $* * * p<0.001, * * p<0.01$, $* p<0.05$. Source: Statistics Norway (2020a, b, c, d, e, f, g, h, i, j) and further processed by the author

which resulted in little more than 1000 . Hence, verbal intentions, accompanied by an unconditional grant that makes such an increase feasible to municipalities, are only implemented to a limited extent by Norwegian municipalities.

For the reference municipality, the results in Table 2 imply a direct cost elasticity of $e_{H H} \approx-0.94$ for home care, and $e_{N N} \approx-0.90$ for institutional care, and as documented in the Online Supplemental Appendix, the corresponding cost elasticities for most other municipalities deviate only slightly from these magnitudes. Hence, to conclude, municipalities with a high unit cost for home care seem to adjust the capacity of the home care sector so that their expenditures on home care are almost unaffected by their high unit cost for home care, and similarly for nursing home care. Compensated elasticities are shown in the Online Supplemental Appendix Table 4.

Consider now a stylized change in the age structure of the population in the reference municipality, with population size and structure in all other municipalities unchanged. Total population is also kept constant in the reference municipality, but the population is assumed to become older, resulting in an increase in the magnitude of the variable Expdeaths by 0.005. For sake of simplicity, it is assumed that the share of young (below 15) in the reference municipality is kept constant. These assumptions may seem unrealistic, but taken together they imply an age structure in the reference municipality that after the increase in Expdeaths is very similar to the age structure in the municipality with the highest magnitude of Expdeaths in the data set. The increase in Expdeaths shifts $w_{H}^{\bar{m}}$ down from 0.539 to 0.435 , and $w_{N}^{\bar{m}}$ shifts up, thereby increasing the unit cost of the aggregate good LTC by $21.9 \%$, i.e. by 734 USD(6649 NOK). Assume now that per capita block grants to the reference municipality increase by the same amount, reflecting that Norwegian municipalities through the central government grant system are supposed to be fully insured against additional costs of serving an old population. Next, upper-stage estimation results are used for calculating the impact of the following factors on the per capita LTC budget: (a) the increase in Expdeaths, (b) the increase in the unit cost of LTC (Cost index), and (c) the increase in the municipality's per capita incomes from central government grants (Income). The 
result is an increase in per capita expenditures on LTC in the reference municipality of $34.4 \%$. However, expenditures on home care only increase by $11 \%$, while the increase for nursing homes is $65 \%$. Notice that these results are the outcomes of decisions at three levels of the Norwegian public sector: the central government, the upper level of the municipality, and within the LTC sector. The strong reallocation of resources towards the nursing home sector as a consequence of population ageing is mainly because need, measured by Expdeaths, plays a prominent role in the allocation, both at the upper level of the municipality and within the LTC sector. Economic factors (i.e. central government compensation and reallocation within municipalities) also play a role but are less important than need. From the stylized case above it seems warranted to conclude that the insurance element in the Norwegian LTC system mainly is accommodated in the internal decision processes of municipalities. This is an important observation that may have relevance not only to the Scandinavian context but to multilevel governments more in general.

Three caveats should be added to the analysis. First, combining the result that ageing in the reference municipality increases the unit cost of LTC by $21.9 \%$ with the result that per capita expenditures on LTC in the reference municipality increase by $34.4 \%$, implies an overcompensation of $10.3 \%$. This may be related to a simplistic ageing assumption, where the share of young in the population is kept constant. Second, a complete examination of whether the Norwegian system of LTC implies full insurance against the consequences of loss of functionality at high age would have to consider how nursing home capacity and the expenditures on home care are allocated to individuals. However, an examination of this issue would require other types of data than used in the present study. Third, notice that the income-dependent user fees for care services do not exhaust individual incomes, particularly for home care. Hence, in Norway, there is substantial, but not complete, insurance against the financial consequences of frailty.

Finally, consider the role of political variables for the choice between home care and nursing home care. First, from Table 2, notice that the allocation decisions seem to be unaffected by whether the municipality has a socialist or nonsocialist majority. However, municipalities where political power is concentrated, as measured by the Herfindahl index, allocate a larger share of LTC resources to nursing home care. A final interesting result, although statistically significant only when estimation is carried out by maximum likelihood, is that the higher the age of the median voter, the larger the share of the LTC budget allocated to home care. A possible reason for why high-age median voters (between 50 and 60) favor home care over nursing home care may be that they realize that in a not too distant future they might want to receive home care, while they may be too myopic to account for the possibility that later in life they may need nursing home care. This interpretation is in accordance with Finkelstein and McGarry (2006), who found that even much older people (average age 78) grossly underestimate the probability that within 5 years they will enter a nursing home. 


\section{Concluding Remarks}

This article is based on estimating a linear version of the AIDS for the LTC sector in Norwegian municipalities. The results indicate that home care is a luxury, while nursing home care is a necessity, i.e., that an increase in a municipality's LTC expenditures will lead to a substantially stronger expansion in home care than in nursing home care. However, as seen in relation to municipalities' total revenues, both home care and nursing home care seem to be necessities. The estimated cost elasticities indicate that municipalities only substitute home care for high-cost nursing home care to a limited degree. Rather, for both types of care, high unit costs seem to be associated with a smaller volume of the same type of care.

Based on a stylized case, Norwegian municipalities seem to function quite well as an insurance mechanism for LTC. The internal resource allocation processes in municipalities are the most important elements in the insurance of those in need of LTC. The fact that Norwegian municipalities are compensated by the central government for having an old population, seems to play a more modest role for the amount of resources they allocate to LTC.

This article replaces age-class variables by a variable that measures the number of individuals expected to die within one year. The results clearly indicate that this measure has many advantages compared to the traditional age-class measures used by most researchers. Not only did this turn out to be a statistically superior measure, but it is also a more intuitive measure and in line with the arguments made by Zweifel et al. (1999) that proximity to death matters more for the use of health care than distance from birth does.

The data used in this article made it possible to split the LTC sector into only two sub-sectors. In future research, one should consider the possibility of splitting it into more sectors, thereby coming even closer to the specific services that matter for users. Another interesting avenue of research would be to examine how municipalities that have made different choices for the capacity of nursing homes and home care allocate resources within each of these sectors to individual users.

Results obtained in this paper may be of relevance not only for Norway, but also for other countries where LTC is provided through local governments, particularly the other Nordic countries, and perhaps also the UK. Among these countries, the variation in political-administrative systems is not much larger than the variation among Norwegian municipalities. The results for the lower-stage allocation may to some extent be valid also in a wider context. For instance, wherever LTC is provided through a care organization responsible for home care as well as for nursing home care, and operating under a hard budget constraint, it seems reasonable that home care will be a luxury and nursing home care a necessity. However, data on the allocation decisions of different organizations may be hard to obtain. Until such data are collected and analyzed, the results reported in this article may function as substitute, albeit imperfect, for knowledge.

Acknowledgements This paper is part of the project Care for the Needy, financed by the Research Council of Norway. Thanks to Jochen Jungeilges, Juha Tuomala, Fred Schroyen, Andreu Arenas-Jal, the editor and a referee to this journal, for comments on earlier versions of this paper. 
Funding Open Access funding provided by University of Agder.

Open Access This article is licensed under a Creative Commons Attribution 4.0 International License, which permits use, sharing, adaptation, distribution and reproduction in any medium or format, as long as you give appropriate credit to the original author(s) and the source, provide a link to the Creative Commons licence, and indicate if changes were made. The images or other third party material in this article are included in the article's Creative Commons licence, unless indicated otherwise in a credit line to the material. If material is not included in the article's Creative Commons licence and your intended use is not permitted by statutory regulation or exceeds the permitted use, you will need to obtain permission directly from the copyright holder. To view a copy of this licence, visit http://creativecommons.org/licenses/by/4.0/.

\section{References}

Barr, J. L., \& Davis, O. A. (1966). An elementary political and economic theory of the expenditures of local governments. Southern Economic Journal, 33(2), 149-165.

Borge, L. E., Haraldsvik, M., Løyland, K., \& Nyhus, O. H. (2013). The cost key for care services: analysis of unit costs, coverage rates, expenditures, and user fees. (Delkostnadsnøkkelen for pleie og omsorg: Analyser av enhetskostnader, dekningsgrader, utgifter og brukerbetaling.) SØF-rapport 04/13. Trondheim: Senter for økonomisk forskning.

Deaton, A., \& Muellbauer, J. (1980a). Economics and consumer behavior. Cambridge: Cambridge University Press.

Deaton, A., \& Muellbauer, J. (1980b). An almost ideal demand system. American Economic Review, 70(3), 312-326.

Dudzinski, C. S., Erekson, O. H., \& Ziegert, A. L. (1998). Estimating an hedonic translog cost function for the home health care industry. Applied Economics, 30(9), 1259-1267.

Falch, T., \& Strøm, B. (2006). Local flexibility in wage setting: Evidence from the Norwegian local public sector. Empirical Economics, 31(1), 113-142.

Filippini, M. (2001). Economies of scale in the Swiss nursing home industry. Applied Economics Letters, 8(1), 43-46.

Finkelstein, A., \& McGarry, K. (2006). Multiple dimensions of private information: Evidence from the longterm care insurance market. American Economic Review, 96(4), 938-958.

Heien, D., \& Pompelli, G. (1989). The demand for alcoholic beverages: Economic and demographic effects. Southern Economic Journal, 55(3), 759-770.

Kjøs, В. Ø., \& Havig, A. K. (2016). An examination of quality of care in Norwegian nursing homes - a change to more activities? Scandinavian Journal of Caring Sciences, 30(2), 330-339.

Lovdata. (2012). Regulation of user charges for municipalities' health and care services (Forskrift om egenandel for kommunale helse- og omsorgstjenester). https://ovdata.no/dokument/SF/forskrift/201112-16-1349/KAPITTEL_2\#KAPITTEL_2. Accessed 13 September 2020.

McKay, N. L. (1988). An econometric analysis of costs and scale economies in the nursing home industry. Journal of Human Resources, 23(1), 57-75.

Mommaerts, C. (2018). Are coresidence and nursing homes substitutes? Evidence from Medicaid spend-down provisions. Journal of Health Economics, 59, 125-138.

Moschini, G. (1995). Units of measurement and the Stone index in demand system estimation. American Journal of Agricultural Economics, 77(1), 63-68.

Norges Bank. (2020). Exchange rates. https:/www.norges-bank.no/en/topics/Statistics/exchange_rates/. Accessed 1 August 2020.

Pashardes, P. (1993). Bias in estimating the almost ideal demand system with the Stone index approximation. Economic Journal, 103(419), 908-915.

Poterba, J. M. (1997). Demographic structure and the political economy of public education. Journal of Policy Analysis and Management, 16(1), 48-66.

Rahman, M., Galarraga, O., Zinn, J. S., Grabowski, D. C., \& Mor, V. (2016). The impact of certificate-of-need laws on nursing home and home health care expenditures. Medical Care Research and Review, 73(1), 85-105.

Sivesind, K. H. (2017). The changing roles of for-profit and nonprofit welfare provision in Norway, Sweden, and Denmark. In K. H. Sivesind \& J. Saglie (Eds.), Promoting active citizenship: Markets and choice in Scandinavian welfare (pp. 32-74). London: Palgrave Macmillan.

Statistics Norway. (2020a). Statbank: Table 07459 https://www.ssb.no/en/statbank/table/07459. Accessed 13 June 2020.

Statistics Norway. (2020b). Statbank: Table 10325 https://www.ssb.no/en/sok?sok=10325. Accessed 13 June 2020. 
Statistics Norway. (2020c). Statbank: Table 08425 https://www.ssb.no/en/sok?sok=08425. Accessed 13 June 2020.

Statistics Norway. (2020d). Statbank: Table 05212 https://www.ssb.no/en/sok?sok=05212. Accessed 16 June 2020.

Statistics Norway. (2020e). Statbank: Table 03027 https://www.ssb.no/en/sok?sok=03027. Accessed 16 June 2020.

Statistics Norway. (2020f). Statbank: Table 01182 https://www.ssb.no/en/sok?sok=01182. Accessed 20 June 2020.

Statistics Norway. (2020g). Statbank: Table 06445 https://www.ssb.no/en/sok?sok=06445. Accessed 21 June 2020.

Statistics Norway. (2020h). Statbank: Table 07790 https://www.ssb.no/en/sok?sok=07790. Accessed 26 June 2020.

Statistics Norway. (2020i). Statbank: Table 04469 https:/www.ssb.no/en/sok?sok=04469. Accessed 8 July 2020.

Statistics Norway. (2020j). Statbank: Table 12134 https://www.ssb.no/en/statbank/table/12134. Accessed 11 July 2020.

Stone, J. R. N. (1953). The measurement of consumers' expenditure and behaviour in the United Kingdom, 1920-1938 (Vol. 1). Cambridge: Cambridge University Press.

Vitiliano, D. F., \& Toren, M. (1994). Cost and efficiency in nursing homes: A stochastic frontier approach. Journal of Health Economics, 13(5), 281-300.

Zellner, A. (1962). An efficient method of estimating seemingly unrelated regressions and tests for aggregation bias. Journal of the American Statistical Association, 57(298), 348-368.

Zweifel, P., Felder, S., \& Meiers, M. (1999). Ageing of population and health care expenditure: A red herring? Health Economics, 8(6), 485-496.

Publisher's Note Springer Nature remains neutral with regard to jurisdictional claims in published maps and institutional affiliations. 